\title{
Tollip interaction with STAT3: a novel mechanism to regulate human airway epithelial responses to type 2 cytokines
}

Niccolette Schaunaman ${ }^{1}$, Kris Genelyn Dimasuay ${ }^{1}$, Monica Kraft ${ }^{2,4^{*}}$ and Hong Wei Chu ${ }^{1,3^{*}}$ (D)

\begin{abstract}
Background: Toll-interacting protein (Tollip) is one of the key negative regulators in host innate immunity. Genetic variation of Tollip has been associated with less Tollip expression and poor lung function in asthmatic patients, but little is known about the role of Tollip in human airway type 2 inflammatory response, a prominent feature in allergic asthma.
\end{abstract}

Objective: Our goal was to determine the role and underlying mechanisms of Tollip in human airway epithelial responses such as eotaxin to type 2 cytokine IL-13.

Methods: Tollip deficient primary human airway epithelial cells from 4 healthy donors were generated by the gene knockdown approach and stimulated with IL-13 to measure activation of transcription factor STAT3, and eotaxin-3, an eosinophilic chemokine.

Results: Following IL-13 treatment, Tollip deficient cells had significantly higher levels of STAT3 activation and eotaxin-3 than the scrambled control counterpart, which was reduced by a STAT3 inhibitor. Interaction between Tollip and STAT3 proteins was identified by co-immunoprecipitation.

Conclusion: Our results, for the first time, suggest that Tollip inhibits excessive eotaxin-3 induction by IL-13, in part through the interaction and inhibition of STAT3. These findings lend evidence to the potential of a STAT3 inhibitor as a therapeutic target, especially for type 2 inflammation-high asthmatics with Tollip deficiency.

Keywords: Tollip, STAT3, Airway epithelial cells, LL-13, Type 2 inflammation, Protein-protein interaction

\section{Background}

Toll-interacting protein (Tollip) is a multifunctional immune regulator under both physiological and pathological conditions [1]. One of the major functions of Tollip in innate immunity is to prevent excessive proinflammatory responses [2]. Reduced Tollip expression and subsequent dysfunction of the biological system

\footnotetext{
*Correspondence: mkraft@deptofmed.arizona.edu; chuhw@njhealth.or ${ }^{3}$ Department of Medicine, National Jewish Health, 1400 Jackson Street, Room A639, Denver, CO 80206, USA

${ }^{4}$ Department of Medicine, College of Medicine, Tucson, 1501 Campbell Avenue, Office 6334, Tucson, AZ 85724, USA

Full list of author information is available at the end of the article
}

due to genetic variation or pathological conditions have been reported in various human diseases including cancer, Alzheimer's disease, tuberculosis, atopic dermatitis, pulmonary fibrosis and infections [3-8]. Our recent work demonstrated that Tollip single nucleotide polymorphism (SNP) rs5743899 is associated with reduced Tollip expression in airway epithelial cells and poor lung function in asthma patients [9]. More specifically, asthma subjects carrying the G allele (AA or AG) of rs5743899 had significantly lower FEV1/FVC ratio than those carrying the $A$ allele (AA), indicating airflow limitation. Mechanistically, human airway epithelial cells with AG or GG of rs5743899 expressed less Tollip, but produced original author(s) and the source, provide a link to the Creative Commons licence, and indicate if changes were made. The images or other third party material in this article are included in the article's Creative Commons licence, unless indicated otherwise in a credit line to the material. If material is not included in the article's Creative Commons licence and your intended use is not permitted by statutory regulation or exceeds the permitted use, you will need to obtain permission directly from the copyright holder. To view a copy of this licence, visit http://creativecommons.org/licenses/by/4.0/. The Creative Commons Public Domain Dedication waiver (http://creativecommons.org/publicdomain/zero/1.0/) applies to the data made available in this article, unless otherwise stated in a credit line to the data. 
significantly higher levels of neutrophilic chemokine IL-8 and eosinophilic chemokine eotaxin-3 than the cells with AA following the stimulation with IL-13 and rhinovirus, a major risk factor in asthma exacerbations. Asthma is a heterogeneous chronic respiratory condition that encompasses several different endotypes [10]. One such endotype is type 2-high asthma, that is distinguished by the presence of type 2 cytokines (e.g. IL-13), and accumulation and activation of eosinophils [11-13], and increased severity of the disease [12, 14]. Regulation of eosinophilic inflammation by innate immune factors has not been well studied. The major goal of this report is to determine a novel role of Tollip in the production of pro-eosinophilic mediator eotaxin-3 in human primary airway epithelial cells, a first line host defense mechanism in respiratory diseases. IL-13 is known to induce eosinophilic inflammation (e.g. production of eotaxin-3) by activating transcription factor STAT6 in airway epithelial cells [15]. Recently, STAT3, another member of the STAT transcription factor family [16], has been found to be activated by IL-13 by our group and others $[17,18]$. Moreover, airway epithelial STAT3 has been shown to be essential in initiating type 2 inflammation in an allergic asthma mouse model [19]. Whether and how Tollip may regulate airway epithelial responses (e.g. eotaxin production) to IL-13 remain unclear. In this report, we presented a novel hypothesis that Tollip interacts with STAT3 to inhibit its activation and the ensuing type 2 inflammation (e.g. eotaxin production).

\section{Methods}

Isolation of human tracheobronchial epithelial (HTBE) cells HTBE cells were isolated as previously described [20] from de-identified donor lungs that were not suitable for transplantation. The four selected donors were nonsmokers with no prior history of lung disease (Table 1). The Institutional Research Board at National Jewish Health approved this research.

\section{Lentivirus-mediated knockdown of Tollip in HTBE cells}

HTBE cells from four healthy donors were transduced with human Tollip or control (scrambled) short hairpin

Table 1 Subject demographics

\begin{tabular}{lllll}
\hline Subject & Gender & Age (years) & Smoking history & Cause of death \\
\hline 1 & Male & 36 & Never & Anoxia \\
2 & Female & 68 & Never & Stroke \\
3 & Male & 50 & $\begin{array}{l}\text { Non-smoker } \\
(>12 \text { years })\end{array}$ & Stroke \\
4 & Male & 60 & Never & Stroke \\
\hline
\end{tabular}

RNA (shRNA) obtained from Genecopoeia (Bethesda, MD) as we have previously described [17]. Briefly, 293FT cells grown in a $60 \mathrm{~mm}$ culture dish in Dulbecco's modified Eagles Medium containing 10\% FBS, with no antibiotics, were transduced with the lentivirus constructs to produce supernatants containing packaged lentivirus. Lentivirus-containing supernatants were then used to transduce HTBE cells in six-well plates $[17,20,21]$ to generate Tollip deficient and Tollip-sufficient cells, which were selected and further expanded on puromycin resistant irradiated 3T3 fibroblasts in the presence of $1 \mu \mathrm{g} / \mathrm{ml}$ puromycin and a Rho kinase inhibitor.

\section{Treatment of HTBE cells}

HTBE cells from four healthy donors, either transduced or not-transduced, were seeded onto collagen coated 24-well plates at a seeding density of $5 \times 10^{4}$ cells/well in $500 \mu \mathrm{l}$ of BronchiaLife (Lifeline Cell Technologies, Frederick, MD) and grown in submerged culture until 80-90\% confluency. For experiments with IL-13 alone, cells were treated with $10 \mathrm{ng} / \mathrm{ml}$ of IL-13 (PeproTech, Rocky Hill, NJ) or $0.01 \%$ BSA as a control in BronchiaLife. For STAT3 inhibitor experiments, cells were pretreated with $50 \mu \mathrm{M}$ of STAT3 Inhibitor VI (S31-201, MilliporeSigma, Burlington, MA) for $30 \mathrm{~min}$ or $0.5 \%$ DMSO in BronchiaLife, after which, $10 \mathrm{ng} / \mathrm{ml}$ of IL-13 was added to appropriate wells. We chose the IL-13 dose and duration of treatment based on our previous publication [18]. Cells and supernatants from both experiments were harvested 24 and $48 \mathrm{~h}$ after IL-13 treatment.

\section{ELISA}

Eotaxin-3 was measured in supernatants using a Human CCL26/Eotaxin-3 DuoSet ELISA kit (R\&D Systems, Minneapolis, MN).

\section{Western blot analysis}

Cells were lysed in radioimmunoprecipitation assay (RIPA) buffer containing protease and phosphatase inhibitors (ThermoFisher, Waltham, MA). Equal amounts of total protein from each cell culture condition were separated by SDS-PAGE, transferred onto PVDF membranes, blocked with blocking buffer, and incubated with the following primary antibodies overnight at $4{ }^{\circ} \mathrm{C}$ : Tollip monoclonal antibody (Enzo Life Sciences International, Farmingdale, NY), Phospho-Stat3 antibody (Tyr705, Cell Signaling Technology, Danvers, MA), Stat3 antibody (Cell Signaling Technology), and Beta-Actin antibody (Santa Cruz Biotechnology, Dallas, TX). After washes in PBS with $0.1 \%$ Tween-20, membranes were incubated with the appropriate horseradish peroxidase (HRP)linked secondary antibodies and developed using a Fotodyne imaging system (Fotodyne, Inc., Harland WI). 
Densitometry was performed using the NIH ImageJ software.

\section{Statistical analysis}

Student's $t$ test was used for two group comparisons. A P-value of $<0.05$ was considered significant.

\section{Tollip deficiency promotes STAT3 activation and type 2 inflammatory responses}

We utilized Tollip deficient (knockdown, KD) primary human HTBE cells (Fig. 1A) from four healthy donors to explicitly demonstrate a role of Tollip in airway epithelial type 2 inflammatory response. As shown in Fig. 1B, Tollip KD cells have significantly higher levels of STAT3 activation (phosphorylation) than the scrambled control cells after $24 \mathrm{~h}$ of IL-13 treatment. Subsequently ( $48 \mathrm{~h}$ after IL-13 treatment), Tollip KD cells produced more eotaxin-3, a potent eosinophil chemokine, than the control (scrambled shRNA) cells (Fig. 1C). Of note, eotaxin-3 was not detectable in cells without IL-13 treatment. Our data provided the first evidence that Tollip deficiency exaggerated type 2 cytokine response, including excessive STAT3 activation and production of eotaxin-3.

\section{STAT3 activation is responsible for exaggerated type 2 inflammatory response in Tollip deficient cells}

To determine if STAT3 activation is responsible for eotaxin-3 production, we first inhibited STAT3 activity using a highly selective inhibitor (S31-201) in Tollip sufficient cells. As shown in Fig. 2A, the STAT3 inhibitor significantly reduced STAT3 activity $24 \mathrm{~h}$ after IL-13 treatment, which was followed by significant reduction of eotaxin-3 protein at $48 \mathrm{~h}$ of IL-13 treatment (Fig. 2B).

Next, we determined if more eotaxin- 3 production in IL-13-treated Tollip KD cells is dependent on excessive STAT3 activation. As shown in Fig. 3, IL-13 mediated excessive eotaxin-3 production in Tollip KD cells were significantly reduced by a STAT3 inhibitor.

While our results continue to provide more evidence of the involvement of STAT3 in type 2 inflammation, for
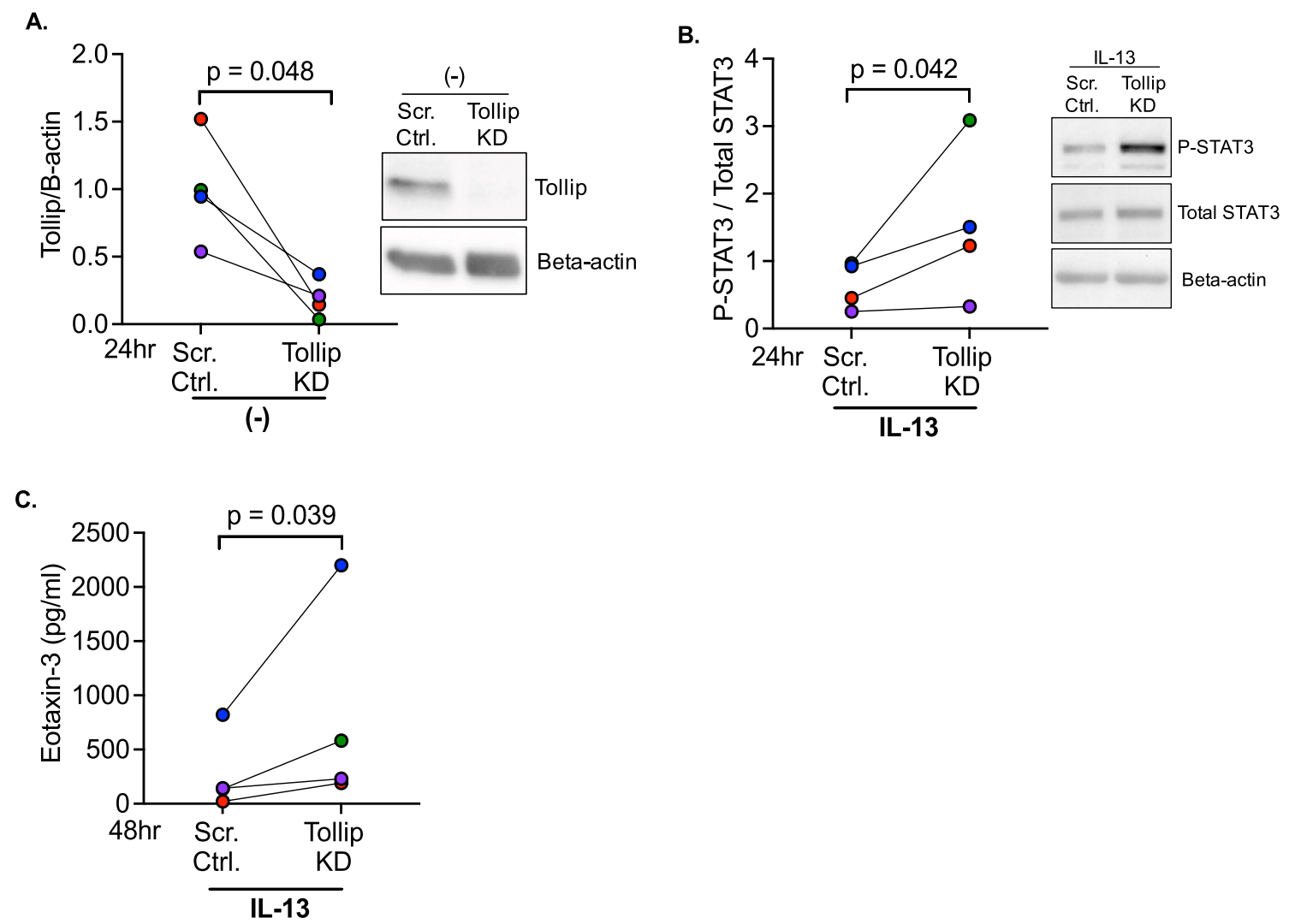

Fig. 1 Tollip deficiency promotes STAT3 activation and inflammatory response to IL-13. A Western blot image showing Tollip knockdown (KD) using the shRNA approach in tracheobronchial epithelial cells. Data was normalized to the scrambled control. B Increased STAT3 activation in Tollip KD cells vs. scrambled control after $24 \mathrm{~h}$ of IL-13 treatment. Data was normalized to the scrambled control cells with IL-13 treatment. C Significantly higher eotaxin-3 levels in Tollip KD cells vs. scrambled control cells after $48 \mathrm{~h}$ of IL-13 treatment. P-values represent a paired student's $t$-test. Data are from four healthy human donors. Each dot represents one donor. Data from one donor is the mean of three technical replicates 
A.

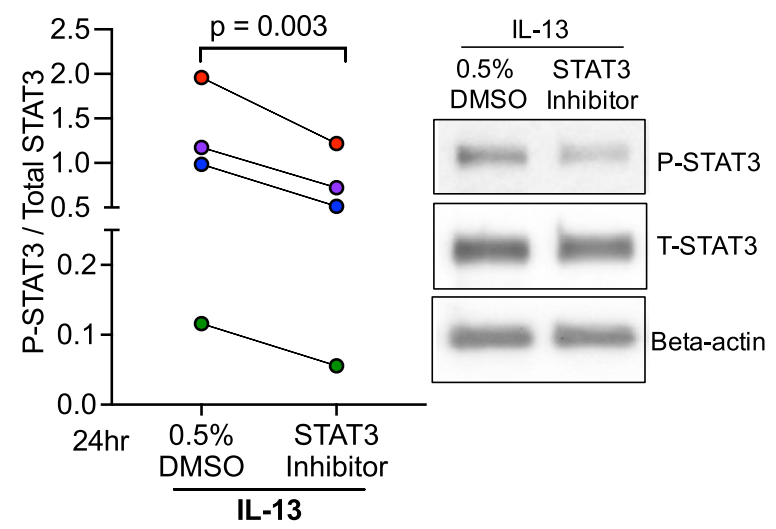

B.

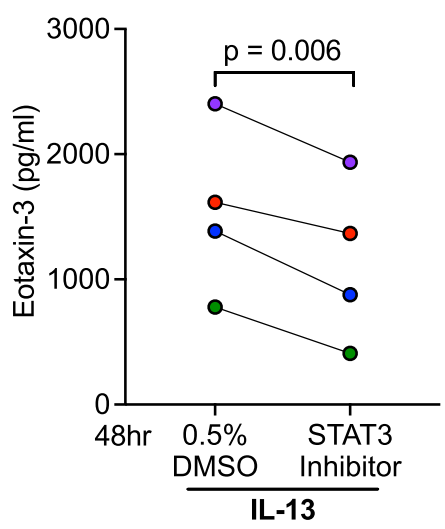

Fig. 2 STAT3 inhibition reduces the type 2 inflammatory response in IL-13 treated Tollip sufficient tracheobronchial epithelial cells. A IL-13 treatment increased activation/phosphorylation of STAT3, which was inhibited by a STAT3 inhibitor. Data was normalized to the IL-13 treatment with 0.5\% DMSO. B A STAT3 inhibitor significantly reduced the levels of IL-13-induced eotaxin-3 in supernatants. P-values represent a paired student's $t$-test. Data are from four healthy human donors. Each dot represents one donor. Data from one donor is the mean of three technical replicates

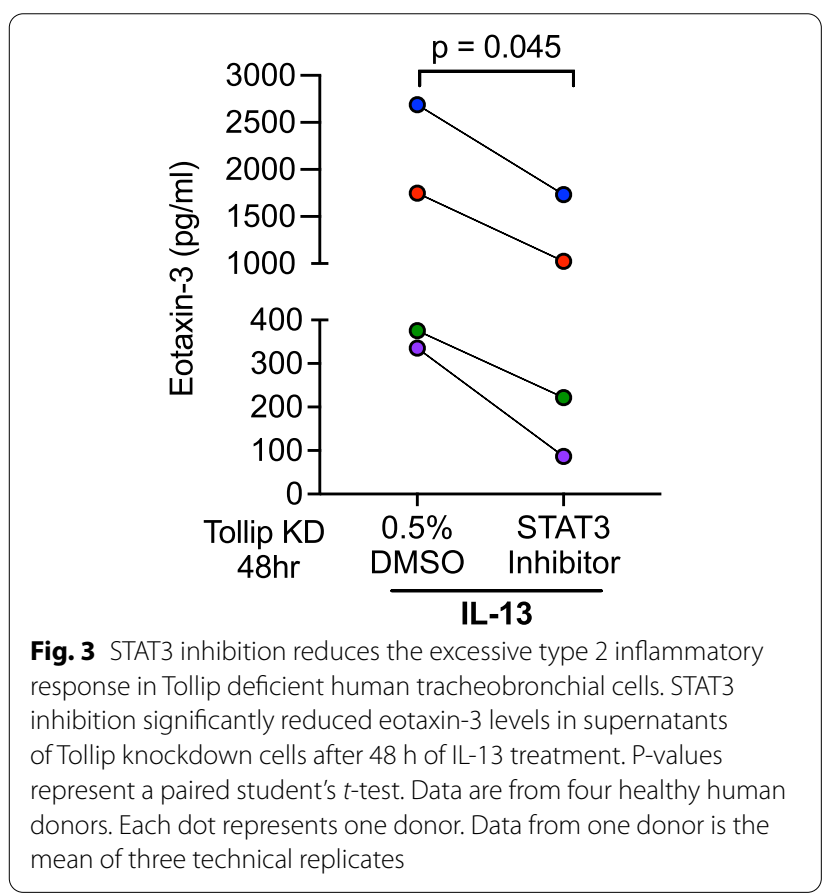

the first time we showed that Tollip is able to reduce IL13-induced type 2 inflammatory response (i.e. eotaxin-3) through the inhibition of STAT3 activation. By using a conditional STAT3 knockout mouse model, SimeonePenney and colleagues demonstrated that STAT3 signaling in airway epithelium was required for an eosinophilic inflammatory response following allergen challenges [19]. Others have shown that STAT3 is required for T helper 2 cell development [22]. Together, our data and others support the potential of using STAT3 inhibitors as

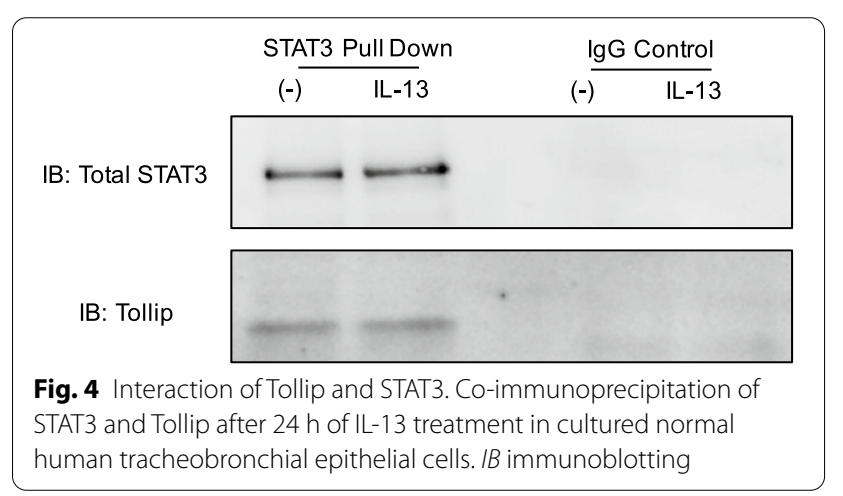

a potential therapy in combating excessive type 2 inflammatory response seen in patients with Tollip deficiency.

\section{Tollip interacts with STAT3}

To determine how Tollip may inhibit STAT3 activation, we sought to identify if Tollip interacts with STAT3 at the protein level. As shown in Fig. 4, STAT3 was successfully pulled down via co-immunoprecipitation (Co-IP) assay. Importantly, the STAT3 Co-IP protein complex contained Tollip, indicating a protein-protein interaction of Tollip and STAT3. Thus, we are the first to identify a novel protein-protein interaction of STAT3 and Tollip. Tollip is comprised of three domains. At present, we do not know how Tollip interacts with or binds to STAT3. To clearly demonstrate how Tollip regulates IL-13-medaited STAT3 activation and function, future studies will be needed to clarify which Tollip protein domain is responsible for its interaction with STAT3, and if Tollip/ STAT3 interaction subsequently promotes the degradation of STAT3. 
As data from our current study are from healthy donors that have not been genotyped for Tollip SNP rs5743899, future studies can include airway epithelial cells from human subjects with different Tollip genotypes to study whether varying levels of Tollip expression are associated with STAT3 activation levels and pro-inflammatory responses following type 2 cytokine stimulation. Additionally, we and others may utilize an IL-13 treatment or allergen challenge model in Tollip deficient mice, in conjunction with the STAT3 inhibitor to determine the in vivo role of Tollip and STAT3 interaction in type 2 inflammation.

\section{Conclusions}

The current study has further demonstrated Tollip as an important regulator in human diseases. Our discovery that Tollip deficiency promotes airway type 2 inflammatory response possibly through the interaction or inhibition with STAT3 likely changes the therapeutic strategies (e.g. use of a STAT3 inhibitor) in treating patients with Tollip deficiency.

\section{Abbreviations \\ Tollip: Toll-interacting protein; Scr. Ctrl.: Scrambled control; KD: Knockdown; HTBE: Human tracheobronchial epithelial; P-STAT3: Phosphorylated STAT3; Co-IP: Co-immunoprecipitation.}

\section{Acknowledgements}

Not applicable.

\section{Authors' contributions}

NS and HWC conceived the study. NS performed all experiments and data analysis. NS, KGD, MK, and HWC discussed and interpreted all results. NS wrote the manuscript. All authors read and approved the final manuscript.

\section{Funding}

This work was supported by the NIH Grant: U19AI125357. This funding source was not involved in the preparation of data or the manuscript.

\section{Availability of data and materials}

The datasets used and/or analyzed during the current study are available from the corresponding author on reasonable request.

\section{Declarations}

Ethics approval and consent to participate

To isolate primary human tracheobronchial epithelial cells, we obtained human trachea from de-identified organ donors whose lungs were not suitable for transplantation and were donated for medical research through the International Institute for the Advancement of Medicine (Edison, $\mathrm{NJ}$ ), or Donor Alliance of Colorado. The Institutional Review Board (IRB) at National Jewish Health deemed this research as non-human subjects research.

\section{Consent for publication}

Not applicable.

\section{Competing interests}

M.K. has received grants from Sanofi, ALA, Chiesi, and AstraZeneca; royalties from Elsevier; and consulting fees from AstraZeneca and Sanofi outside the submitted work. The rest of the authors declare that they have no competing interests.

\section{Author details}

${ }^{1}$ National Jewish Health, Denver, CO, USA. ${ }^{2}$ University of Arizona, Tucson, AZ, USA. ${ }^{3}$ Department of Medicine, National Jewish Health, 1400 Jackson Street, Room A639, Denver, CO 80206, USA. ${ }^{4}$ Department of Medicine, College of Medicine, Tucson, 1501 Campbell Avenue, Office 6334, Tucson, AZ 85724, USA.

Received: 9 June 2021 Accepted: 24 January 2022

Published online: 16 February 2022

\section{References}

1. Kowalski EJA, Li L. Toll-interacting protein in resolving and non-resolving inflammation. Front Immunol. 2017:8:511.

2. Shah JA, Emery R, Lee B, Venkatasubramanian S, Simmons JD, Brown $M$, et al. TOLLIP deficiency is associated with increased resistance to Legionella pneumophila pneumonia. Mucosal Immunol. 2019;12(6):1382-90.

3. Rogers EN, Jones DZ, Kidd NC, Yeyeodu S, Brock G, Ragin C, et al. Toll-like receptor-associated sequence variants and prostate cancer risk among men of African descent. Genes Immun. 2013;14(6):347-55.

4. Schimming TT, Parwez Q, Petrasch-Parwez E, Nothnagel M, Epplen JT, Hoffjan S. Association of toll-interacting protein gene polymorphisms with atopic dermatitis. BMC Dermatol. 2007;7:3.

5. Shah JA, Vary JC, Chau TT, Bang ND, Yen NT, Farrar JJ, et al. Human TOLLIP regulates TLR2 and TLR4 signaling and its polymorphisms are associated with susceptibility to tuberculosis. I Immunol. 2012;189(4):1737-46.

6. Oldham JM, Ma SF, Martinez FJ, Anstrom KJ, Raghu G, Schwartz DA, et al. TOLLIP, MUC5B, and the response to $\mathrm{N}$-acetylcysteine among individuals with idiopathic pulmonary fibrosis. Am J Respir Crit Care Med. 2015;192(12):1475-82.

7. de Araujo FJ, da Silva LD, Mesquita TG, Pinheiro SK, Vital Wde S, ChrusciakTalhari A, et al. Polymorphisms in the TOLLIP gene influence susceptibility to cutaneous Leishmaniasis caused by Leishmania guyanensis in the Amazonas state of Brazil. PLoS Negl Trop Dis. 2015;9(6):e0003875.

8. Chen K, Yuan R, Geng S, Zhang Y, Ran T, Kowalski E, et al. Toll-interacting protein deficiency promotes neurodegeneration via impeding autophagy completion in high-fat diet-fed ApoE(-/-) mouse model. Brain Behav Immun. 2017:59:200-10.

9. Huang C, Jiang D, Francisco D, Berman R, Wu Q, Ledford JG, et al. Tollip SNP rs5743899 modulates human airway epithelial responses to rhinovirus infection. Clin Exp Allergy. 2016;46(12):1549-63.

10. Kuruvilla ME, Lee FE, Lee GB. Understanding asthma phenotypes, endotypes, and mechanisms of disease. Clin Rev Allergy Immunol. 2019:56(2):219-33.

11. Woodruff PG, Modrek B, Choy DF, Jia G, Abbas AR, Ellwanger A, et al. T-helper type 2-driven inflammation defines major subphenotypes of asthma. Am J Respir Crit Care Med. 2009;180(5):388-95.

12. Fahy JV. Type 2 inflammation in asthma - present in most, absent in many. Nat Rev Immunol. 2015;15(1):57-65.

13. Robinson D, Humbert M, Buhl R, Cruz AA, Inoue H, Korom S, et al. Revisiting type 2-high and type 2-low airway inflammation in asthma: current knowledge and therapeutic implications. Clin Exp Allergy. 2017:47(2):161-75.

14. Zeiger RS, Schatz M, Li Q, Chen W, Khatry DB, Gossage D, et al. High blood eosinophil count is a risk factor for future asthma exacerbations in adult persistent asthma. J Allergy Clin Immunol Pract. 2014;2(6):741-50.

15. Goenka S, Kaplan MH. Transcriptional regulation by STAT6. Immunol Res. 2011;50(1):87-96.

16. Pernis AB, Rothman PB. JAK-STAT signaling in asthma. J Clin Invest. 2002;109(10):1279-83.

17. Dakhama A, Al Mubarak R, Pavelka N, Voelker D, Seibold M, Ledford JG, et al. Tollip inhibits ST2 signaling in airway epithelial cells exposed to type 2 cytokines and rhinovirus. J Innate Immun. 2020;12(1):103-15.

18. Francisco D, Wang Y, Conway M, Hurbon AN, Dy ABC, Addison KJ, et al. Surfactant protein-A protects against IL-13-induced inflammation in asthma. J Immunol. 2020;204(10):2829-39. 
19. Simeone-Penney MC, Severgnini M, Tu P, Homer RJ, Mariani TJ, Cohn L, et al. Airway epithelial STAT3 is required for allergic inflammation in a murine model of asthma. J Immunol. 2007;178(10):6191-9.

20. Wu Q, Jiang D, Smith S, Thaikoottathil J, Martin RJ, Bowler RP, et al. IL-13 dampens human airway epithelial innate immunity through induction of IL-1 receptor-associated kinase M. J Allergy Clin Immunol. 2012;129(3):825-33 e2.

21. Schaunaman N, Sanchez A, Dimasuay KG, Pavelka N, Numata M, Alam R, et al. Interleukin 1 receptor-like 1 (IL1RL1) promotes airway bacterial and viral infection and inflammation. Infect Immun. 2019. https://doi.org/10. 1128/IAl.00340-19.

22. Stritesky GL, Muthukrishnan R, Sehra S, Goswami R, Pham D, Travers J, et al. The transcription factor STAT3 is required for T helper 2 cell development. Immunity. 2011;34(1):39-49.

23. Zhu L, Wang L, Luo X, Zhang Y, Ding $Q$, Jiang $X$, et al. Tollip, an intracellular trafficking protein, is a novel modulator of the transforming growth factor-beta signaling pathway. J Biol Chem. 2012;287(47):39653-63.

24. Lo YL, Beckhouse AG, Boulus SL, Wells CA. Diversification of TOLLIP isoforms in mouse and man. Mamm Genome. 2009;20(5):305-14.

\section{Publisher's Note}

Springer Nature remains neutral with regard to jurisdictional claims in published maps and institutional affiliations.

- fast, convenient online submission

- thorough peer review by experienced researchers in your field

- rapid publication on acceptance

- support for research data, including large and complex data types

- gold Open Access which fosters wider collaboration and increased citations

- maximum visibility for your research: over $100 \mathrm{M}$ website views per year

At BMC, research is always in progress.

Learn more biomedcentral.com/submissions 